\title{
NIH scientists pressed to maintain standards
}

Washington. The scientific directors of the 24 institutes that make up the US National Institutes of Health (NIH) will lose some of their powers of patronage and face tough performance monitoring under reforms being backed by both Harold Varmus, the director of NIH, and by congressional decision-makers.

The reforms have been proposed by an independent high-powered panel set up by Congress. In a report released last week, the panel says that the $\$ 1.3$ billion in-house research programme, based at the main NIH campus at Bethesda, Maryland, is too fragmented, and faces a mediocre future unless steps are taken to revamp it.

The report proposes new structures to monitor and control the quality of the intramural programme of each of the institutes and centres that make up $\mathrm{NIH}$, as well as a new board that would vet all appointments of tenured research staff.

It also contains proposals for the step-bystep renewal of the Clinical Center, the unique but dilapidated 450-bed research hospital at the heart of the Bethesda campus. These include the construction of a new 250-bed hospital and the renovation of existing laboratories in the centre.

Varmus plans to use the report as ammunition in his drive to impose more consistent standards across NIH, which the report describes as "balkanized". He also wants the $\mathrm{NIH}$ intramural programme to become a supreme centre of excellence at which the best young biomedical researchers will aspire to work.

But this is a tall order, given the financial resources of some of the universities and private institutions competing for the same people. Varmus's room for manoeuvre is also restricted by the high degree of autonomy the institutes enjoy.

The congressional subcommittee in charge of funding NIH asked for the report last autumn, chiefly because of its concern about the cost of renewing the Clinical Center: estimates have ranged from $\$ 900$ million for repair to $\$ 1.6$ billion for full reconstruction.

Percentage of NIH papers ranked within 300 most cited articles published each year

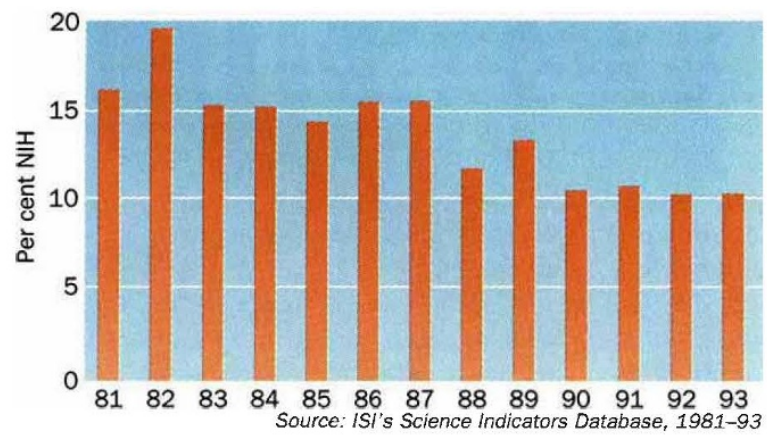

The panel, co-chaired by Gail Cassell of the University of Alabama at Birmingham and Paul Marks of the Memorial Sloan-Kettering Cancer Center, New York, found that the balkanization of the intramural programme "has contributed to unevenness in quality, quality control and productivity" at NIH.

It recommends that the institutes appoint more genuinely independent scientists to their boards of scientific counsellors, and that these boards in turn do more to keep an eye on the scientific directors, whose alleged omnipotence has been a focus of criticism at NIH.

The institutes are also asked to construct an annual planning process to divide resources sensibly between the intramural programme and the extramural one, which consumes the bulk of NIH's \$11-billion budget. Anthony Fauci's National Institute for Allergy and Infectious Diseases has a process which, the report suggests, the others should use as a model.

Another recommendation is that all tenure appointments be vetted by a centrally appointed board of NIH scientists serving staggered terms, instead of by the board of scientific directors as at present. Mike Gottesman, acting deputy NIH director in charge of the intramural programme, who would appoint this new board, denies that the change would centralize power. "It'll be a more diverse group of people, somewhat more separate from the administrative side of the programme," he says.

The panel says that the intramural programme's share of the NIH budget should not grow above its present 11.3 per cent, and that weaker elements should be cut back to fund renewal of the Clinical Center. But it did not question the fundamental need for a large intramural programme, as some critics have done. "A strong intramural programme is essential for a strong extramural programme," says Marks.

$\mathrm{NIH}$ will spend \$2.5 million over the next year drawing up more detailed plans for the renewal of the Clinical Center. These will probably involve the refurbishment of parts of the existing building, the demolition of other parts and the construction of the new hospital as an annex.

Many of the proposed reforms have been suggested before, but Marks says he is optimistic that this set will be carried through because of support from Varmus, the Health Secretary, Donna Shalala, and the key staff members on con-

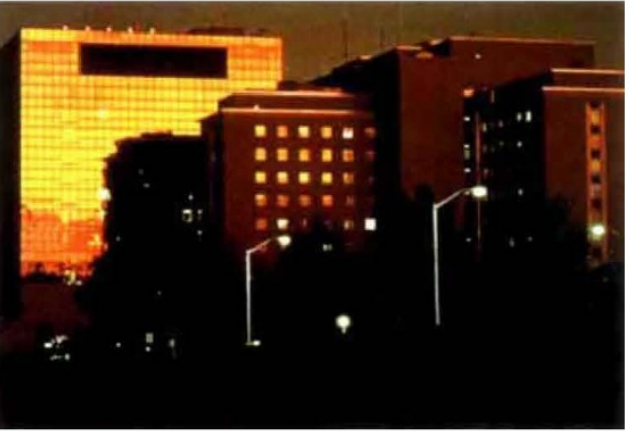

Where next? NIH's Clinical Center.

gressional committees.

Some statistical evidence supports the popular perception that standards have declined at NIH over the past decade (see chart below). But its defenders point out that the proliferation of centres of excellence in biomedical research elsewhere in the United States makes a relative decline almost inevitable. Varmus says he is as confident as ever that the intramural programme can be reinvigorated.

Colin Macilwain

\section{Postgraduate plans under fire in UK}

London. Britain's Royal Society has rejected as "educationally unnecessary" a proposal by the Office of Science and Technology (OST) to require all those wishing to pursue a $\mathrm{PhD}$ to undergo an initial year of training, leading to a new MRes qualification.

The OST's proposal was one of the key recommendations in last year's white paper on science. This announced the government's intention to ensure that a master's year should become "the normal initial postgraduate qualification for research students supported by the research councils."

Detailed proposals of how this scheme might work were published in a consultation document last year by the OST. But in its reply, published last week, the Royal Society echoes the feelings of many professional scientific bodies that the goals being pursued by the government could equally well be achieved by other means, such as the gradual introduction of four-year undergraduate courses.

"We are not against the MRes in principle, but feel it is not the only solution to the problems that the government has identified," says one individual involved in preparing the society's response.

Not all responses to the government's proposals have been as critical. According to the Confederation of British Industry, there has been a positive response from some engineering employers, while the new Engineering and Physical Sciences Research Council is believed to be enthusiastic. 